\title{
INCREASING HAIRDRESSING COMPLIANCE WITH A CHILD WITH AUTISM SPECTRUM DISORDERS
}

\author{
Anja Gajići, \\ Bojana Arsić, \\ Aleksandra Bašić, \\ Dragana Maćešić-Petrović, \\ Ružica Zdravković Parezanović \\ University of Belgrade, \\ Faculty for Special Education and Rehabilitation, \\ Visokog Stevana 2, Belgrade, \\ Serbia
}

\begin{abstract}
:
The diagnosis of autism spectrum disorders (ASD) itself can include problems with hyper responsiveness to different sensory stimuli. These difficulties can lead to different maladaptive behavioral manifestations and prevent children diagnosed with ASD from participating in certain activities. The aim of the present case study was to examine the effectiveness of shaping procedure application in order to increase compliance with haircutting with a six year old boy diagnosed with ASD. The procedure used for increasing compliance while getting a haircut was shaping and we divided the intervention into two phases. Phase one involved teaching the participant to tolerate the presence of the hair clipper on his head, while phase two consisted of increasing participant's toleration of the sound emitted by the hair clipper. Generalization probe involved taking the participant into a hair salon, where he would receive hair grooming performed by a professional hair stylist. The child mastered phase one in 54 trials that were conducted during five sessions and mastered the goal time in phase two in 89 trials that were conducted during four sessions. In conclusion, shaping procedure appears to be an effective and efficient training procedure for teaching skills that are important for future everyday functioning in society of children with ASD, as well as basic hygiene skills, such as hair cutting. Study limitations and future research implications are discussed.
\end{abstract}

Keywords: haircut, shaping, autism, compliance

${ }^{i}$ Correspondence: email anjuskagajic@gmail.com, bojana.arsic57@gmail.com 


\section{Introduction}

Individuals with autism spectrum disorder (ASD) experience qualitative impairments in communication and reciprocal social interaction and a pattern of restricted, repetitive interests and behaviors (American Psychiatric Association, 2013). The diagnosis itself can include problems with hyper responsiveness to different sensory stimuli (Baranek et al., 2005), and the most common ones are in auditory processing. These difficulties in processing certain sounds from the environment (O'Connor, 2012) can lead to different maladaptive behavioral manifestations (Ayres, 1991) and affect the individuals' overall quality of life (Dunn, 1997) and prevent them from participating in certain activities.

Refusal to participate in certain activities is a commonly reported problem in children with ASD (Lovaas, 1993) and some authors have found that it is exhibited by up to $65 \%$ of the population (Kalb \& Loeber, 2003). Previous research has shown that children with ASD can display distress while participating in different settings that can lead to acting out behaviors and display of fear and anxiety (Thurgate \& Heppel, 2005), which can consequently lead to higher rates of co-occurring mental health problems (Russell et al., 2016; Simonoff et al., 2008).

There are several procedures used for increasing compliance of children with ASD with different procedures (McComas, Wacker \& Cooper, 1998), such as haircutting, and one of the most commonly used is shaping. Shaping procedure refers to differential reinforcement of successive approximations to the desired behavior, while previous responses are put on extinction (Skinner, 1953). It is based on systematic desensitization, which refers to a set of procedures designed to reduce unwanted negative emotional reactions to stimuli that initially produce fear or anxiety, by allowing individuals to ignore irrelevant stimuli and attend to relevant stimuli (Carnagey, Anderson \& Bushman, 2007). Systematic desensitization has been proven to be effective in the treatment of fears (Lazarus, 1961), anxiety (Paul \& Shannon, 1966), self-control (Goldfried, 1971) and avoidance behavior (Davison, 1968).

The aim of the present case study was to examine the effectiveness of shaping procedure application in order to increase compliance with haircutting with a six year old boy diagnosed with ASD.

\section{Material and Methods}

\subsection{Participant}

At the time of the procedure implementation, the participant was six years old and he attended preschool. His sessions mostly consisted of Verbal Behavior Intervention (VBI) following Sundberg's Verbal Behavior Milestones and Assessment protocol (VB-MAPP, Sundberg, 2008).

The participant could not tolerate hair cutting with a hair clipper, he was agitated by the sound, and when he was taken to a hairdresser salon, he would cover his ears and start screaming indistinct noises and crying. We defined problem behavior as placing arms and palms on his head, covering ears, emitting high frequency noises, pushing the 
hairdresser with extremities, raising the shoulders to cover the neck area, bending the head forward or backwards in order to escape the hair clipper, screaming and crying. The child showed great distress when passing a hairdressing salon, where he would take his parents by their hands and try to walk across the street. As a result of this behavior, the participant's mother cut his hair with scissors in the home bathroom, or while he was asleep. The parents stated that they would like for the participant to be taught tolerating hair clipper, because his hair was always unevenly cut.

\subsection{Materials}

Stimulus preference assessment methods have a strong empirical basis (DeLeon \& Iwata, 1996; Fisher et al., 1992; Pace, Ivancic, Edwards, Iwata \& Page, 1985; Piazza, Fisher, Hagopian, Bowman \& Toole, 1996) in identifying stimuli that can be used in training programs or behavior-reduction programs. When presenting a choice among stimuli in a preference assessment, those stimuli can be concurrently presented in pairs (Fisher et al., 1992) or in an array of multiple stimuli (Carr, Nicolson \& Higbee, 2000; Higbee, Carr \& Harrison, 2000). We conducted a multiple stimulus preference assessment and determined that the reinforcer with highest value for the participant was a snack called Smoki, which is a bite size snack with peanuts.

Other materials used were a stopwatch, which was used to measure the duration of exposure to the sound emitted by a hair clipper and a hair clipper cutting the hair.

\subsection{Setting}

Baseline and training sessions were conducted in a therapy room with approximate size $3 \times 3$ meters and generalization probes were conducted in a hair dresser salon that was the approximate size $4 \times 3$ meters. Training sessions were conducted twice a week, in duration of one hour, so the participant received treatment in a total duration of two hours a week. During generalization sessions, people present in the hair salon were professional hairdresser, the child, a therapist and his father.

\subsection{Design}

A single subject baseline design was used. The child first completed baseline sessions, which were used to take the mean time of a child's tolerance to the sound emitted by a hair clipper. After baseline, a trial based sessions were conducted in order to facilitate the acquisition of the desired skill. Criterion was met when the child engaged in the desired behavior in three consecutive trials, which allowed introduction of the next approximation.

\subsection{Procedure}

\subsubsection{Baseline}

Participants' abilities were probed during baseline by using a multiple-opportunity method (Cooper, Heron \& Heward, 2007) in three consecutive sessions. Baseline data was collected regarding the length of tolerating the sound that was emitted by a hair clipper 
without engaging in inappropriate behavior, where we established that the mean was five seconds.

\subsubsection{Intervention}

The procedure used for increasing compliance during hairdresser procedure was shaping and we divided the intervention into two phases.

Phase one involved teaching the participant to tolerate the presence of the hair clipper on his head. Since the child already could manage five second duration of the sound emitted by a hair clipper, every step involved only five seconds of sound length. All the steps were performed while the child was seated at a chair that was in the corner of the therapy room and the hair clipper had on it a safety cap which disables hair cutting. The room was three hundred centimeters wide and we set ten steps to achieve the goal (Table 1).

Table 1: Steps for phase one

\begin{tabular}{|l|l|}
\hline Step number & Distance of the participant and a hair clipper \\
\hline 1 & At the door, 300 centimeters away from the child \\
\hline 2 & 250 centimeters away \\
\hline 3 & 200 centimeters away \\
\hline 4 & 150 centimeters away \\
\hline 5 & 100 centimeters away \\
\hline 6 & 50 centimeters away \\
\hline 7 & 30 centimeters away \\
\hline 8 & 20 centimeters away \\
\hline 9 & Ten centimeters away \\
\hline 10 & On the head \\
\hline
\end{tabular}

Phase two consisted of increasing participant's toleration of the sound emitted by the hair clipper. Since the mean time for tolerating emitted sound was five seconds and the average hair cutting procedure for boys' hair was 300 seconds (as the professional hairdresser stated), we divided this phase into 12 steps (Table 2).

Table 2: Steps for phase two

\begin{tabular}{|l|l|}
\hline Step number & Number of seconds \\
\hline 1 & 10 seconds \\
\hline 2 & 15 seconds \\
\hline 3 & 20 seconds \\
\hline 4 & 30 seconds \\
\hline 5 & 45 seconds \\
\hline 6 & 60 seconds \\
\hline 7 & 90 seconds \\
\hline 8 & 120 seconds \\
\hline 9 & 180 seconds \\
\hline 10 & 200 seconds \\
\hline 11 & 250 seconds \\
\hline 12 & 300 seconds \\
\hline
\end{tabular}


In both phases, all the steps were performed individually, until the participant mastered each step, which involved the lack of disruptive behavior manifestations in three consecutive trials, which included aggressive behaviors, removing or attempting to remove materials, getting out of their seat, using his hands to push against or pull away from the care provider implementing steps and putting his hands on top of his ears and emitting noises.

After the child mastered one step in three consecutive trials, we introduced the next one. Reinforcer was contingent on each successful step completion.

\subsubsection{Generalization probes}

Generalization probe was conducted in a hair salon, where he would receive haircuts from a professional hair stylist. While getting a haircut, the participant had free access to the reinforcer, because we came to a conclusion that a child eating a snack while getting his hair trimmed is not something that would make him socially excluded.

\subsubsection{Dependent measures}

Dependent measures included duration of the sound emitted by a hair clipper in seconds, as well as the distance of the hair clipper from the participants head in meters and centimeters.

\section{Results and Discussion}

The room where sessions occurred was 300 centimeters wide and the implementation was set at that distance. For the first figure, $\mathrm{X}$-axis represents the number of trials and $\mathrm{Y}$ axis represents the distance of the hair clipper from the child. Phase lines refer to each step that was implemented. We decided to represent the number of trials instead of the number of sessions on the $\mathrm{X}$-axis, because each session included several numbers of trials, as well as several steps that were sometimes mastered in one session.

The baseline probe was not conducted, the room where sessions occurred was 300 centimeters wide and we decided to start implementing the procedure from that distance. The steps that were the most difficult for the child, as they required the most trials for introduction of next approximation were first and the second (seven trials followed by eight trials) (Figure 1). As the new steps were introduced, the distance of the hair clipper emitting the sound from the child reduced. The child mastered the goal distance of zero centimeters in 54 trials that were conducted during five sessions. 
Figure 1: Results for phase one

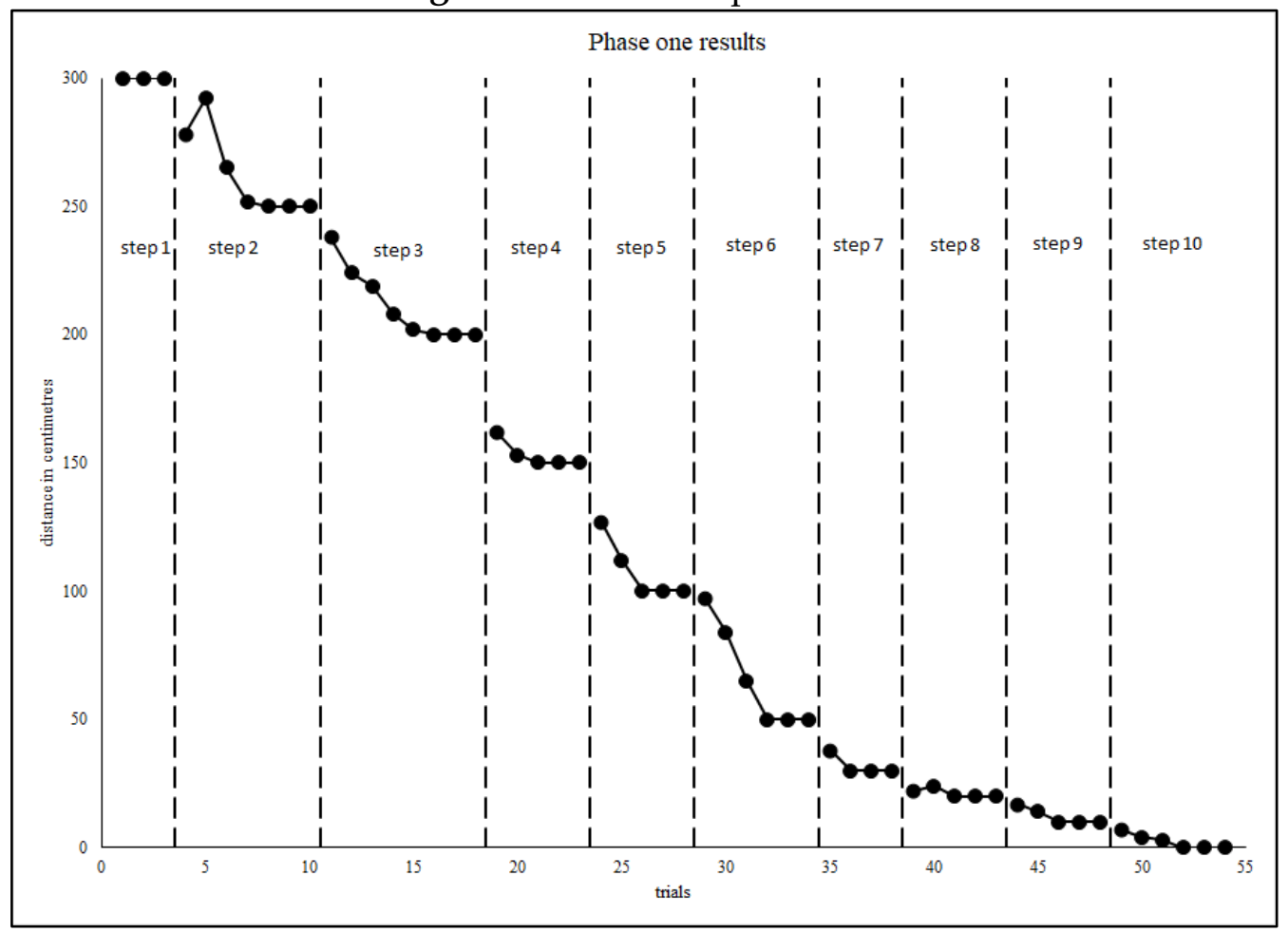

For the second figure, $\mathrm{X}$-axis represents the number of trials and $\mathrm{Y}$-axis represents the duration represented in a number of seconds. Phase lines refer to each step that was implemented. The representation of number of trials instead of number of sessions was explained previously.

Figure 2: Results for phase two

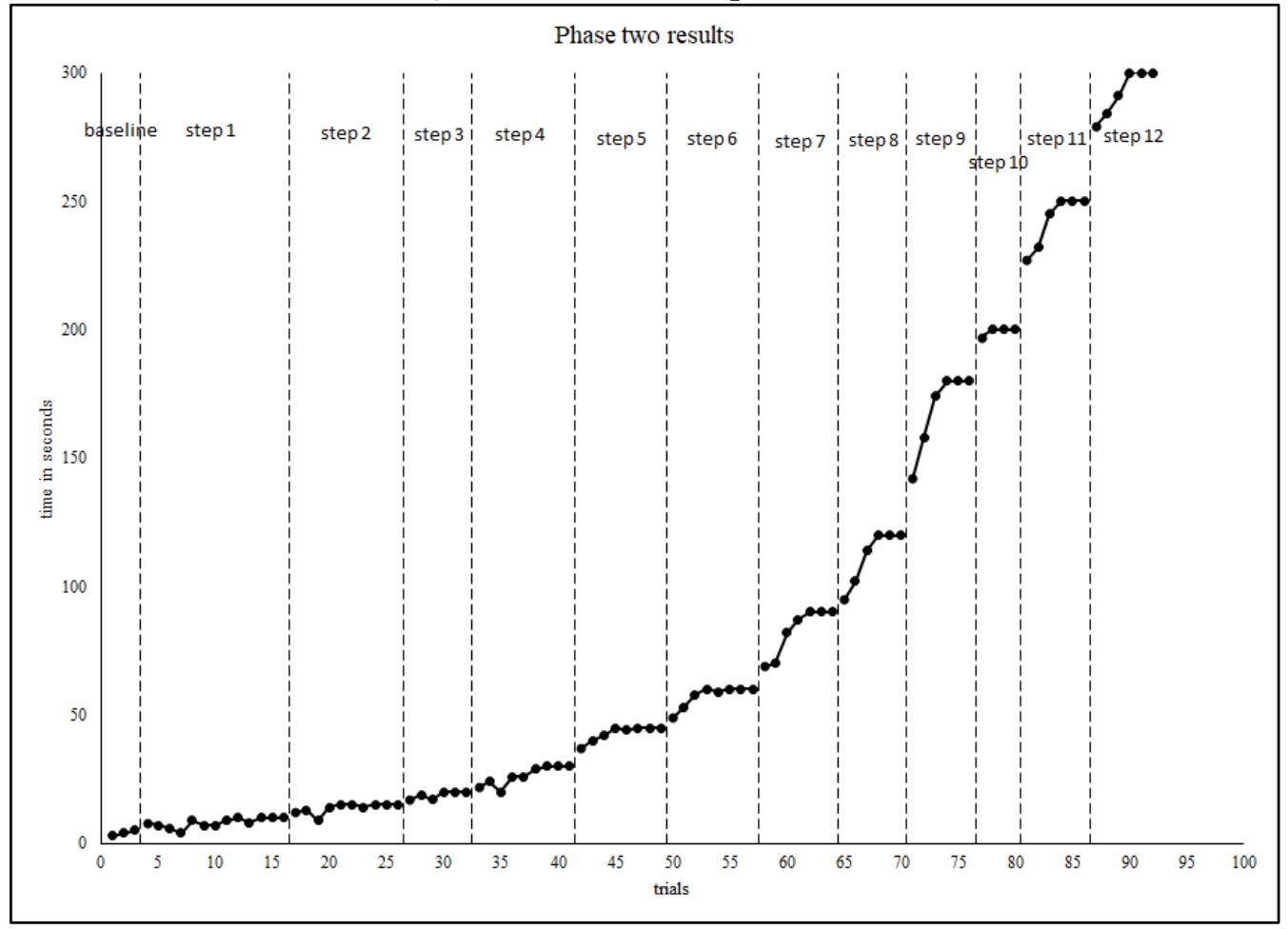


The baseline probe results for phase two indicated that the mean time was five seconds (Figure 2). Mastering the first and second step were the most difficult for the child and required more trials to be mastered (13 and 10 trials). Following the onset of the intervention, the child's mean time increased from the baseline level. The child mastered the goal duration in 89 trials that were conducted during four sessions.

Both graphs indicate that there was a decreasing number of trials needed for mastering each step. The introduction of each new approximation was easier for the child to master and the most difficult steps were in the beginning. This correlates with the exposure to aversive stimuli that was difficult to overcome, because the gradual exposure has just been introduced. The present study supports previously stated efficiency of implementing shaping procedure as a tool for adaptation to the aversive stimulus, as well as a successful tool for teaching children with ASD hygiene skills. Following the implementation of the shaping procedure the child mastered first phase in 54 trials and second phase in 89 trials, a total of 143 trials. The participant demonstrated generalization of the newly acquired skill in different settings (hair salon), as well as with new and unknown people (hairdresser).

Previous study (Buckley, Luiselli, Harper \& Shlesinger, 2020) that focused on increasing tolerance to haircutting of children with ASD by using shaping procedure was focused on two adolescents, 16 and 17 years of age. Their research also included two phases, which were the same as in this paper, with the exception of the number of steps, the first phase has been divided into 16 and the second phase into 11 steps. The children included in their sample required 200 trials on average to master both phases. Another study (Curiel, 2012) used the same procedure for increasing tolerance to haircutting of three children with ASD that were between the ages of four and thirteen required the mean of 33 trials for children to master the skill.

The present study proclaims that since sometimes children with ASD cannot acquire hygiene skills spontaneously, therefore they must be taught. The same findings were reported in the previous studies (Piccin, Crippa, Nobile, Hardan \& Brambilla, 2018; Probst \& Walker, 2017; Veazey, Valentino, Low, McElroy \& LeBlanc, 2016) where all the children from the sample had difficulties in spontaneous adoption of skills needed for maintaining their personal hygiene, therefore they had to be systematically taught step by step.

Children with ASD can often exhibit compliance issues while participating in different procedures, such as medical procedures (Riviere, Becquet, Peltret, Facon \& Darcheville, 2010), physical exams (Cuvo, Reagan, Brandt, Huckfeldt \& Kelly, 2010), or some routine situations (Cavalari, DuBard, Luiselli \& Birtwell, 2013) that happen from time to time, such as going to a hairdresser.

To date there is not enough research addressing compliance with different procedures addressing hygiene habits of children with ASD, especially with getting a haircut. The present study extends research regarding compliance of children with ASD to different procedures, as well as research focused on the use of shaping procedures to increase tolerance to aversive stimuli, by providing the evidence that children with ASD 
can benefit from interventions that implement this procedure in order to obtain better community visibility and participation.

\section{Recommendations}

Future research might focus on applying this procedure with participants with different diagnosis, as well as examining the effectiveness of this protocol implementation by the parents of children with ASD after being trained to apply it independently. Also, future research might include implementing this procedure for other compliance issues in children with ASD, as well as other behavioral problems exhibited by these children that origin from their sensory impairments.

\section{Conclusion}

Shaping procedure was proven to be a successful teaching tool with children with ASD hygiene skills. These results are significant because the child will be able to use the acquired skill in new hair salons and with different hair stylists.

We emphasize that none of the maintenance probes were conducted, because the participants' parents stated that the acquired skill continued to be present each time he visited the hairdresser salon. The parents also notified the therapist that the child showed great excitement when going to the hair salon, and often asked to get his haircut. We accentuate the deficiency of IOA as one of the biggest limitations of our study.

In conclusion, shaping procedure appears to be an effective and efficient training procedure for teaching skills that are important for everyday functioning in a society of children with ASD, as well as basic hygiene skills, such as hair cutting.

\section{Conflict of Interest Statement}

The authors declare no conflicts of interests.

\section{About the Authors}

Anja Gajić - Research assistant and teaching associate at University of Belgrade, Faculty for Special education and rehabilitation. Certified Registered Behavior Technician. Areas of interest: autism spectrum disorders, behavior analysis, early intervention, selfinjurious behavior.

Bojana Arsić - Research assistant and teaching associate at University of Belgrade, Faculty for Special education and rehabilitation. Certified Registered Behavior Technician. Areas of interest: autism spectrum disorders, behavior analysis, early intervention, communication development, self-help skills.

Aleksandra Bašić - Teaching assistant at University of Belgrade, Faculty for Special education and rehabilitation. Areas of interest: methodology in special education, dance therapy, intellectual disabilities, Montessori Method, assistive technology.

Dragana Maćešić-Petrović - Full time professor at University of Belgrade, Faculty for Special education and rehabilitation, as well as University of Novi Sad, Medical faculty. 
Areas of interest: intellectual disability, hearing impairments, developmental neuropsychology, assistive technology, sensomotor integration, dance and movement therapy.

Ružica Zdravković Parezanović - PhD student at University of Belgrade, Faculty for Special education and rehabilitation. Working at speech and language center Logopedilište, Belgrade, Serbia. Certified psychomotor reeducation specialist. Areas of interest: burnout syndrome, assistive technology, sensomotor integration, creativity in teaching.

\section{References}

American Psychiatric Association. (2013). Diagnostic and statistical manual of mental disorders (Vol. 5th ed). Arlington: VA: American Psychiatric Publishing

Ayres, A. (1972). Sensory integration and learning disorders. Los Angeles: Western Psychological Services.

Baranek, G. T., Parham, L. D., \& Bodfish, J. W. (2005). Sensory and Motor Features in Autism: Assessment and Intervention. In F. R. Volkmar, R. Paul, A. Klin, \& D. Cohen (Eds.), Handbook of autism and pervasive developmental disorders: Assessment, interventions, and policy (p. 831-857). John Wiley \& Sons, Inc. https://doi.org/10.1002/9780470939352.ch6

Buckley, J., Luiselli, J., Harper, J., \& Shlesinger, A. (2020). Teaching students with autism spectrum disorder to tolerate haircutting. Journal of Applied Behavior Analysis, 53(4), 2081-2089. doi: 10.1002/jaba.713

Carr, J., Nicolson, A., \& Higbee, T. (2000). Evaluation of a brief multiple-stimulus preference assessment in a naturalistic context. Journal of Applied Behavior Analysis, 33(3), 353-357. doi: 10.1901/jaba.2000.33-353

Cavalari, R., DuBard, M., Luiselli, J., \& Birtwell, K. (2013). Teaching an adolescent with autism and intellectual disability to tolerate routine medical examination: Effects of a behavioral compliance training package. Clinical Practice in Pediatric Psychology, 1(2), 121-128. doi: 10.1037/cpp00000138.

Cooper, J. O., Heron, T. E., \& Heward, W. L. (2007). Applied behavior analysis (2nd edition). Upper Saddle River, NJ: Pearson Education.

Cuvo, A., Reagan, A., Ackerlund, J., Huckfeldt, R., \& Kelly, C. (2010). Training children with autism spectrum disorders to be compliant with a physical exam. Research in Autism Spectrum Disorders, 4(2), 168-185. doi: 10.1016/j.rasd.2009.09.001

Daly, E., Wells, N., Swanger-Gagné, M., Carr, J., Kunz, G., \& Taylor, A. (2009). Evaluation of the multiple-stimulus without replacement preference assessment method using activities as stimuli. Journal of Applied Behavior Analysis, 42(3), 563-574. doi: 10.1901/jaba.2009.42-563

Davison, G. (1968). Systematic desensitization as a counterconditioning process. Journal of Abnormal Psychology, 73(2), 91-99. doi: 10.1037/h0025501 
DeLeon, I., \& Iwata, B. (1996). Evaluation of a multiple-stimulus presentation format for assessing reinforcer preferences. Journal of Applied Behavior Analysis, 29(4), 519-533. doi: 10.1901/jaba.1996.29-519

Dunn, W., \& Westman, K. (1995). Sensory Profile. University of Kansas Medical Center, Kansas City, KS.

Fisher, W., Piazza, C., Bowman, L., Hagopian, L., Owens, J., \& Slevin, I. (1992). A comparison of two approaches for identifying reinforcers for persons with severe and profound disabilities. Journal of Applied Behavior Analysis, 25(2), 491-498. doi: 10.1901/jaba.1992.25-491

Goldfried, M. (1971). Systematic desensitization as training in self-control. Journal of Consulting and Clinical Psychology, 37(2), 228-234. doi: 10.1037/h0031974

Higbee, T. S., Carr, J. E., Harrison, C. D. (2000). Further evaluation of the multiplestimulus preference assessment. Research in Developmental Disabilities, 21(1), 61-73.

Hugo, C. (2012). The use of contingent reinforcement to increase tolerance during haircut routines in children with autism (published master's thesis). College of Science and Mathematics, California State University, Fresno.

Kalb, L. M., \& Loeber, R. (2003). Child disobedience and noncompliance: A review. Pediatrics, 111(3), 641-652. doi: 10.1542/peds.111.3.641

Lazarus, A. (1961). Group therapy of phobic disorders by systematic desensitization. The Journal of Abnormal and Social Psychology, 63(3), 504-510. doi: 10.1037/h0043315

Lovaas, O. I. (1993). The development of a treatment research project for developmentally disabled and autistic children. Journal of Applied Behavior Analysis, 26(4), 617-630. doi: 10.1901/jaba.1993.26-617

McComas, J. J., Wacker, D. P., Cooper, L. J., Peck, S., Golonka, Z., Millard, T., et al. (2000). Effects of the high-probability request procedure: Patterns of responding to lowprobability requests. Journal of Developmental and Physical Disabilities, 12, 157-171.

Carnagey, N., Anderson, C., \& Bushman, B. (2007). The effect of video game violence on physiological desensitization to real-life violence. Journal of Experimental Social Psychology, 43(3), 489-496. doi: 10.1016/j.jesp.2006.05.003

O'Connor, K. (2012). Auditory processing in autism spectrum disorder: A review. Neuroscience \& Biobehavioral Reviews, 36(2), 836-854. doi: 10.1016/j.neubiorev.2011.11.008

Pace, G., Ivancic, M., Edwards, G., Iwata, B., \& Page, T. (1985). Assessment of stimulus preference and reinforcer value with profoundly retarded individuals. Journal of Applied Behavior Analysis, 18(3), 249-255. doi: 10.1901/jaba.1985.18-249

Paul, G., \& Shannon, D. (1966). Treatment of anxiety through systematic desensitization in therapy groups. Journal of Abnormal Psychology, 71(2), 124-135. doi: 10.1037/h0023172

Piazza, C., Fisher, W., Hagopian, L., Bowman, L., \& Toole, L. (1996). Using a choice assessment to predict reinforcer effectiveness. Journal of Applied Behavior Analysis, 29(1), 1-9. doi: 10.1901/jaba.1996.29-1

Piccin, S., Crippa, A., Nobile, M., Hardan, A., \& Brambilla, P. (2017). Video modeling for the development of personal hygiene skills in youth with autism spectrum 
disorder. Epidemiology and Psychiatric Sciences, 27(2), 127-132. doi: $10.1017 / \mathrm{s} 2045796017000610$

Probst, K., \& Walker, V. (2017). Using the System of Least Prompts to Teach Personal Hygiene Skills to a High School Student with Comorbid Visual Impairment and Autism Spectrum Disorder. Journal of Visual Impairment \& Blindness, 111(6), 511526. doi: 10.1177/0145482x1711100603

Russell, A., Murphy, C., Wilson, E., Gillan, N., Brown, C., \& Robertson, D. et al. (2015). The mental health of individuals referred for assessment of autism spectrum disorder in adulthood: A clinic report. Autism, 20(5), 623-627. doi: $10.1177 / 1362361315604271$

Simonoff, E., Pickles, A., Charman, T., Chandler, S., Loucas, T., \& Baird, G. (2008). Psychiatric Disorders in Children with Autism Spectrum Disorders: Prevalence, Comorbidity, and Associated Factors in a Population-Derived Sample. Journal of the American Academy of Child \& Adolescent Psychiatry, 47(8), 921-929. doi: 10.1097/chi.0b013e318179964f

Skinner, B. F. (1953). Science and human behavior. New York: Macmillan.

Sundberg, M. L. (2008). Verbal behavior milestones assessment and placement program: The VBMAPP. Concord, CA: AVB Press.

Thurgate, C., Heppel, S. (2005). Needle phobia: Changing venepuncture practice in ambulatory care. Paediatric Nursing, 17(9), 15-28. doi: 10.7748/paed.17.9.15.s22

Veazey, S., Valentino, A., Low, A., McElroy, A., \& LeBlanc, L. (2015). Teaching Feminine Hygiene Skills to Young females with Autism Spectrum Disorder and Intellectual Disability. Behavior Analysis in Practice, 9(2), 184-189. doi: 10.1007/s40617-015-00650

Riviere, V., Becquet, M., Peltret, E., Facon, B., \& Darcheville, J. (2011). Increasing compliance with medical examination requests directed to children with autism: effects of a high-probability request procedure. Journal of Applied Behavior Analysis, 44(1), 193-197. doi: 10.1901/jaba.2011.44-193 
Anja Gajić, Bojana Arsić, Aleksandra Bašić, Dragana Maćešić-Petrović, Ružica Zdravković Parezanović INCREASING HAIRDRESSING COMPLIANCE WITH A CHILD WITH AUTISM SPECTRUM DISORDERS

Creative Commons licensing terms

Authors will retain the copyright of their published articles agreeing that a Creative Commons Attribution 4.0 International License (CC BY 4.0) terms will be applied to their work. Under the terms of this license, no permission is required from the author(s) or publisher for members of the community to copy, distribute, transmit or adapt the article content, providing a proper, prominent and unambiguous attribution to the authors in a manner that makes clear that the materials are being reused under permission of a Creative Commons License. Views, opinions and conclusions expressed in this research article are views, opinions and conclusions of the author(s). Open Access Publishing Group and European Journal of Special Education Research shall not be responsible or answerable for any loss, damage or liability caused in relation to/arising out of conflict of interests, copyright violations and inappropriate or inaccurate use of any kind content related or integrated on the research work. All the published works are meeting the Open Access Publishing requirements and can be freely accessed, shared, modified, distributed and used in educational, commercial and non-commercial purposes under a Creative Commons Attribution 4.0 International License (CC BY 4.0). 